Article

\title{
The Beneficial Effect of Eco-Friendly Green Nanoparticles Using Garcinia mangostana Peel Extract against Pathogenicity of Listeria monocytogenes in Female BALB/c Mice
}

\author{
Afrah F. Alkhuriji ${ }^{1}$, Nada A. Majrashi ${ }^{1}$, Suliman Alomar ${ }^{2}$, Manal F. El-Khadragy ${ }^{1,3}{ }^{(D}$, \\ Manal A. Awad ${ }^{4}\left(\mathbb{D}\right.$, Alaa R. Khatab ${ }^{1}$ and Hany M. Yehia ${ }^{5,6, *(\mathbb{C}}$ \\ 1 Department of Zoology, College of Science, King Saud University, Riyadh 11495, Saudi Arabia; \\ aalkhuriji@ksu.edu.sa (A.F.A.); nada430001386@gmail.com (N.A.M.); dr.alaa-rasmi@hotmail.com (A.R.K.); \\ manalelkhadragy@yahoo.com (M.F.E.-K.) \\ 2 Doping Research Chair, Department of Zoology, College of Science, King Saud University, Riyadh 11495, \\ Saudi Arabia; syalomar@ksu.edu.sa \\ 3 Zoology Department, Faculty of Science, Helwan University, Cairo 11790, Egypt \\ 4 King Abdullah Institute for Nanotechnology, King Saud University, Riyadh 11451, Saudi Arabia; \\ mawad@ksu.edu.sa \\ 5 Department of Food Science and Nutrition, College of Food and Agriculture Science, King Saud University, \\ Riyadh 11451, Saudi Arabia \\ 6 Department of Food Science and Nutrition, Faculty of Home Economics, Helwan University, \\ Cairo 11221, Egypt \\ * Correspondence: hanyehia@ksu.edu.sa
}

Received: 8 February 2020; Accepted: 26 March 2020; Published: 29 March 2020

Simple Summary: Listeria monocytogenes is a resourceful foodborne pathogen triggering listeriosis. It was recently found that the bacterium caused acute and self-limiting delirious gastroenteritis in healthy individuals. In the intestinal tract, L. monocytogenes enters the mucosa directly via enterocytes. Animal models for L. monocytogenes infection have provided many insights into the mechanisms of pathogenesis, and the development of new model systems has allowed the investigation of factors that influence adaptation to the gastrointestinal environment. This study investigated that the oral administration of natural products in association with silver nanoparticles could inhibit oral infection of listeria in BALB/c mice. The effect of natural products biosynthesized silver nanoparticles (Ag-NPs) using Garcinia mangostana peel extract were well-known as the major targets of oral listeria infection in mice. Anti-inflammatory factors are important to treat the dangers of chronic inflammation associated with chronic diseases. The pro-inflammatory cytokine levels, such as interleukin (IL)-1 beta and tumor necrosis factor (TNF)-alpha, decreased in the intestine of mice receiving Ag-NPs using Garcinia mangostana peel extract. Therefore, the current study addresses the beneficial effect of the inflammation and apoptotic signaling pathways in intestine induced by L. monocytogenes.

Abstract: Listeria monocytogenes is a psychrophilic bacterium, which causes widespread zoonosis in the natural environment, and mainly affects goat, sheep, and cattle herds. Recently, we predicted that it can be transmitted through food. It causes listeriosis, a severe infectious disease, which occurs with food contaminated with the pathogenic bacterium. Anti-inflammatory factors are important to treat the dangers of chronic inflammation associated with chronic diseases. Natural foodstuffs have made and are continuing to make vital contributions to the search for new antilisterial agents. The use of natural products in association with silver nanoparticles has drawn attention because of its easy, nonpathogenic, eco-friendly, and economical protocol. Hence, we aimed to biosynthesize silver nanoparticles (Ag-NPs) using Garcinia mangostana peel extract, which was found to be a good source for the synthesis of silver nanoparticles, their formation being confirmed by color change and stability 
in solution, and investigated the antilisterial activity of these nanoparticles in a murine model of $L$. monocytogenes infection. A total of 28 mice were divided into four groups-healthy control, infected, infected mice treated with green Ag-NPs biosynthesized with G. mangostana $(5 \mathrm{mg} / \mathrm{mL})$, and infected mice pretreated with Ag-NPs. From our results, oral treatment with Ag-NPs biosynthesized with $G$. mangostana peel extract resulted in a significant reduction in malondialdehyde (MDA), enhanced antioxidant enzyme activities, and increased the levels of the antiapoptotic protein, compared with the untreated mice. These results indicate that G. mangostana may provide therapeutic value against L. monocytogenes-induced oxidative stress and histopathological alterations, and that these effects may be related to antiapoptotic and antioxidant activities.

Keywords: Garcinia mangostana peel; Listeria monocytogenes; green nanoparticles; mice

\section{Introduction}

The digestive tract is not only important for nutrient digestion and absorption, but it is also the largest immunological organ in the body, protecting against exogenous pathogens [1]. The endogenous gastrointestinal microbial flora plays a fundamentally important role in health and disease; critical functions of the commensal flora include protection against epithelial cell injury, regulation of host fat storage, and stimulation of intestinal angiogenesis [2]. The small intestine is able to absorb far in excess of the body's requirements and as such, large portions of this organ can be removed without deleterious effects. However, changes in absorption and secretion homeostasis can rapidly lead to diarrhea, dehydration, electrolyte disturbance, and malnutrition [3].

The small intestine is a major site for L. monocytogenes invasion. L. monocytogenes is a foodborne pathogen responsible for a disease called listeriosis, which is potentially lethal in immunocompromised individuals. Listeriolysin O (LLO) is a toxin produced by Listeria monocytogenes, and it is the major virulence factor of Listeria. This toxin causes membrane damage. This bacterium was first used as a model to study cell-mediated immunity, and has emerged over the past 20 years as a paradigm in infection biology, cell biology, and fundamental microbiology. The Listeria genus includes Gram-positive, nonsporulating, rod-shaped, aerobic or facultative anaerobic microorganisms. The genus consists of more than 10 species including, L. monocytogenes, L. innocua, L. ivanovii, L. seeligeri, L. grayi, and L. welshimeri $[4,5]$.

The main sources of listeriosis are contaminated foods such as milk and milk products. Several internal or external pathological factors, such as viral, bacterial, and parasitic infections, disrupt the oxidant/antioxidant balance, leading to oxidative stress, including the oxidation of lipids, proteins, and nucleic acids [6,7]. Accumulation of reactive oxygen species (ROS) in cells can damage membrane lipids, which are probably the most susceptible cell components, if not prevented by an appropriate antioxidant scavenging system. Several studies indicate that bacterial infections with high tolerance of the host are the result of defense mechanisms that include enhanced generation of ROS [7].

Treatment of Listeria monocytogenes is often difficult due to the toxic side effects, cost, and the increase in drug resistance due to extensive use of antibiotics. This antibiotic-resistant bacterium has been reported with increasing resistance over the past several decades. The antibiotic resistance of Listeria monocytogenes has necessitated the continued effort to identify new improved antilisterial drugs [6].

Natural products have made and continue to make important contributions to the search for new antibacterial drugs [8]. Mangosteen (Garcinia mangostana) is one of the most desirable tropical fruits of Southeast Asia [9]. The mangosteen plant is mainly cultivated in Indonesia, Malaysia, the Philippines, and Thailand [10], and contains secondary metabolites such as flavonoids and polyphenols. Mangosteen has recently been reported to be a rich source of a class of polyphenols known as xanthones [11]. It has many properties such as antibacterial, antifungal, antioxidant, anti-inflammatory, 
and antitumor activities, and shows promise for cosmetic, medicinal, oral, and pharmacological applications [12].

The use of plants as the production assembly of silver nanoparticles (Ag-NPs) has drawn attention because of its simple, rapid, eco-friendly, nonpathogenic, cost-effective protocol. They also provide large quantities of product and a single-step technique for biosynthetic processes. The reduction and stabilization of silver ions by combining them with biomolecules, such as proteins, amino acids, enzymes, polysaccharides, alkaloids, tannins, phenolics, saponins, and vitamins, which already exist in the plant extracts, have medicinal value [13]. As there is increasing interest in using nanotechnology, some reports suggest that nanoparticles (NPs), for biomedical purposes, could form the bulk of future treatment strategies for different diseases [14]. Furthermore, Allahverdiyev et al.2011 [15] found that Ag-NPs have anti-inflammatory effects by inhibiting metabolic activity through impairing mitochondrial function via oxidative stress. Therefore, in the present study, we investigated the protective role of green nanoparticles using the rind of G. mangostana fruit, against L. monocytogenes-induced oxidative stress in female BALB/c mice.

\section{Materials and Methods}

\subsection{Plant Material and Extract Preparation}

Three kilograms of fresh G. mangostana fruit was collected from the hypermarket at Riyadh city, Saudi Arabia, and carefully washed with deionized water several times to remove dust particles. The fruit was then separated into two parts: one part was air dried to remove the residual moisture, cut into small pieces, and stored in air-tight container. The second part was cut into smaller pieces, loaded onto a tray, and freeze dried on a shelf in a freeze dryer (Labconco 8811 Prospect Ave, Kansas City, MO 64132 , USA). This was then ground into fine powder for further extractions. Freeze dried mangosteen was used in this study according to parameters determined in Table S1 (supplementary materials).

\subsection{Total Phenolic Content}

Total phenolic compound content of G. mangostana extract was assayed by the Folin-Ciocalteu method as described previously [16]. Briefly, $0.1 \mathrm{~mL}$ of the sample's extract was mixed with $2.5 \mathrm{~mL}$ of distilled water in a test tube, and then $0.1 \mathrm{~mL}$ of undiluted Folin-Ciocalteu reagent (Sigma-Aldrich, St. Louis, MO, USA) was added. The solution was mixed well and then allowed to stand for 6 min before adding $0.5 \mathrm{~mL}$ of $20 \%$ sodium carbonate solution. The color was developed for $30 \mathrm{~min}$ at room temperature $\left(20^{\circ} \mathrm{C}\right)$, and the absorbance was measured at $760 \mathrm{~nm}$ using a spectrophotometer (PD 303 UV spectrophotometer, Apel Co., Limited, Saitama, Japan). A blank sample was prepared using $0.1 \mathrm{~mL}$ of methanol instead of the extract. The measurement was compared to a calibration curve of gallic acid solution and expressed as milligram $(\mathrm{mg})$ equivalent (eq.) of gallic acid per gram (g) of dry weight extract.

\subsection{Total Flavonoids}

The aluminum chloride colorimetric method was used to determine the total flavonoid content of $G$. mangostana extract as described previously [17]. Briefly, in a test tube, $50 \mu \mathrm{L}$ of the extract was mixed with $4 \mathrm{~mL}$ of distilled water, $0.3 \mathrm{~mL}$ of $5 \% \mathrm{NaNO}_{2}$ solution, and $0.3 \mathrm{~mL}$ of $10 \% \mathrm{AlCl}_{3} \cdot 6 \mathrm{H}_{2} \mathrm{O}$. The mixture was allowed to stand for $6 \mathrm{~min}$, and then, $2 \mathrm{~mL}$ of $1 \mathrm{~mol} / \mathrm{L} \mathrm{NaOH}$ solution was added; distilled water was subsequently added to bring the final volume to $10 \mathrm{~mL}$. The mixture was allowed to stand for another $15 \mathrm{~min}$, and the absorbance was measured at $510 \mathrm{~nm}$. The total flavonoid content was calculated from a calibration curve, and the result was expressed as mg eq. rutin per $g$ dry weight.

\subsection{DPPH (2,2-diphenyl-1-picrylhydrazyl) Radical Scavenging Activity}

The power of the G. mangostana extract to scavenge DPPH radicals was assayed as described previously [18]. A fresh solution of $0.08 \mathrm{mM}$ DPPH radical in methanol was prepared. Next, $950 \mu \mathrm{L}$ 
of DPPH solution was mixed with $50 \mu \mathrm{L}$ extract and incubated for $5 \mathrm{~min}$. Exactly $5 \mathrm{~min}$ later, the absorbance of the mixture was measured at $515 \mathrm{~nm}$ (PD 303 UV spectrophotometer, Apel Co., Limited, Saitama, Japan). Antioxidant activity (AA) is expressed as percentage inhibition of DPPH radical using the equation: $\mathrm{AA}=100-\left[100 \times\left(\mathrm{A}_{\text {sample }} / \mathrm{A}_{\text {control }}\right)\right]$, where $\mathrm{A}_{\text {sample }}$ is the absorbance of the sample at time, $t=5 \mathrm{~min}$ and $\mathrm{A}_{\text {control }}$ is the absorbance of the control.

\subsection{ABTS [2,4,6-tri(2-pyridyl)-s-triazine] Radical Scavenging Activity}

The ABTS assay was used to determine the DPPH radical scavenging activity according to the method of Gouveia and Castilho (2011) [19]. The ABTS ${ }^{+}$radical solution was prepared by reacting $50 \mathrm{~mL}$ of $2 \mathrm{mM}$ ABTS solution with $200 \mu \mathrm{L}$ of $70 \mathrm{mM}$ potassium persulfate solution. This mixture was stored in the dark for $16 \mathrm{~h}$ at room temperature, and it was stable in this form for 2 days. For each analysis, the $\mathrm{ABTS}^{+}$solution was diluted with $\mathrm{pH} 7.4$ phosphate buffered saline (PBS) solution to an initial absorbance of $0.700 \pm 0.021$ at $734 \mathrm{~nm}$.

This solution was freshly prepared for each set of analysis. To determine the antiradical scavenging activity, an aliquot of $100 \mu \mathrm{L}$ methanolic solution was mixed with $1.8 \mathrm{~mL}$ of $\mathrm{ABTS}^{+}$solution, and the decrease in absorbance at 734 nm (PD 303 UV spectrophotometer, Apel Co., Limited, Saitama, Japan) was recorded during $6 \mathrm{~min}$. The results are expressed as $\mu \mathrm{mol}$ Trolox equivalent per $\mathrm{g}$ of dried extract ( $\mu$ mol eq. Trolox/g), based on the Trolox calibration curve.

\subsection{Ferric Reducing Antioxidant Power (FRAP)}

Ferric reducing antioxidant power (FRAP) was performed as described previously [20]. The FRAP reagent included $300 \mathrm{mM}$ acetate buffer, pH 3.6, $10 \mathrm{mM} \mathrm{2,4,6-Tris(2-pyridyl)-s-triazine} \mathrm{(TPTZ)} \mathrm{in}$ $40 \mathrm{mM} \mathrm{HCl}$, and $20 \mathrm{mM} \mathrm{FeCl}_{3}$ in the ratio of 10:1:1 (v/v/v). A volume of $3 \mathrm{~mL}$ of the FRAP reagent was mixed with $100 \mathrm{~mL}$ of moringa extract in a test tube and incubated with shacking at $37^{\circ} \mathrm{C}$ for $30 \mathrm{~min}$ in a water bath. Reduction of ferric-TPTZ to the ferrous complex formed an intense blue color, which was measured with a UV-visible spectrophotometer (PD 303 UV spectrophotometer, Apel Co., Limited, Saitama, Japan) at $593 \mathrm{~nm}$ after $4 \mathrm{~min}$. The results are expressed in terms of mol eq. Trolox per $g$ of dried sample ( $\mu$ mol eq. Trolox/g).

\subsection{Synthesis of Ag-NPs using the Peel of G. Mangostana}

Green Ag-NPs were synthesized by bioreduction of Ag+ using fresh suspension of G. mangostana fruit. A volume of $5 \mathrm{~mL}$ of the extract was added drop-by-drop to an aqueous solution of $\mathrm{AgNO}_{3}$ $(50 \mathrm{~mL}, 0.1 \mathrm{mM} / \mathrm{mL})$, and was stirred at $45-50{ }^{\circ} \mathrm{C}$ for $30 \mathrm{~min}$. Ultrasonication was applied to the mixed solution for $3 \mathrm{~h}$. The color of the silver nitrate solution changed from colorless to deep brown, indicating the formation of the Ag-NPs. The residual $\mathrm{AgNO}_{3}$ was removed by dialysis against deionized water at $4{ }^{\circ} \mathrm{C}$. The Ag-NPs formed was analyzed by Zetasizer (ZEN 3600, Malvern, UK) and characterized using transmission electron microscopy (TEM) (JEM-1011, JEOL, Akishima, Japan). Furthermore, the green Ag-NP synthesis was confirmed by a UV-Visible spectrophotometer in the range of 200-1000 nm wavelength. The absorption spectra were recorded with Perkin-Elmer Lambda 40 B double-beam spectrophotometer using $1 \mathrm{~cm}$ matched quartz cells. Particles were prepared during $24 \mathrm{~h}$ and used immediately within 1 week. The stability of the Ag-NPs was examined by observing the color of the solution after 20,40,50, and 60 days of storage in a refrigerator at $4{ }^{\circ} \mathrm{C}$. Mice were fed orally with $5 \mathrm{mg} / \mathrm{mL}$ of the green Ag-NPs synthesized from the rind of G. mangostana fruit.

\subsection{Listeria monocytogenes Preparation and Culture}

L. monocytogenes serotype 4a strains acquired from American Type Culture Collection (ATCC 19114), (10 $10 \mathrm{CFU} / \mathrm{mL})$ were used to study mouse oral infection. Activated culture of L. monocytogenes ATCC 19114 was grown on Brain Heart Infusion Agar (Oxoid, CM 1136) and incubated at $37^{\circ} \mathrm{C}$ for $24 \mathrm{~h}$. One colony was picked and inoculated in Brain Heart Infusion broth (Oxoid, CM 1135), for $7 \mathrm{~h}$ on rotary shaker (120 RPM) at $37^{\circ} \mathrm{C}$. Optical density (O.D) at $620 \mathrm{~nm}$ was determined every $1 \mathrm{~h}$, and at 
the same time, the total count was enumerated on Brain Heart Agar. After determining the cells of $10^{10} \mathrm{CFU} / \mathrm{mL}$, (Figures S1 and S2 (supplementary materials)), the cells were centrifuged (5000 rpm for $10 \mathrm{~min}$ ); the supernatant was discarded, and the pellet was washed twice in PBS (Dulbecco A, Oxoid BR0014G, pH 7.3) and then resuspended in $10 \mathrm{~mL}$ of PBS. Infection dose of L. monocytogenes contained above $10^{9} \mathrm{CFU}$, and was orally injected to each mouse according to Angelakopoulos et al., 2002; [21] and Lecuit et al., 1999 [22]. While, the dose used by Golnazarian et al., 1989 [23] ranged from 3.74 to $6.45 \log 10 \mathrm{CFU}$, we challenged mice orally with $10^{10} \mathrm{CFU} /$ daily using gavage.

\subsection{Experimental Protocol}

For the in vivo experiment, BALB/c female mice $(\mathrm{n}=28 ; 8$ weeks old) were obtained from VACSERA (Giza, Egypt). The mice were challenged with L. monocytogenes by oral injection of $0.3 \mathrm{~mL}$ of RPMI 1640 media. The animals were housed in wire-bottomed cages under standard conditions of illumination with a 12-h light-dark cycle and at a temperature of $25 \pm 1{ }^{\circ} \mathrm{C}$ for 1 week until the beginning of treatment. The animals were provided with tap water and a balanced diet ad libitum. All experiments were performed in accordance with the European Community Directive (95/701/EEC). The animal care procedures agreed with the National Institutes of Health (NIH) Guidelines for the Care and Use of Laboratory Animals, eighth edition, and were approved by the Institutional Animal Ethics Committee for Laboratory Animal Care at the Zoology Department, Faculty of Science, Helwan University (Approval number: HU/Z/012-19).

The animals were randomly divided into four groups with seven animals in each group and treated as follows for 2 weeks:

Group I: Normal noninfected negative control group.

Group II: Infected untreated positive control group: mice were orally infected with L. monocytogenes $10^{10}$ CFU orally/day.

Group III: Infected mice with L. monocytogenes $10^{10} \mathrm{CFU}$ orally/day and treated at the same time with green nanoparticles biosynthesized with G. mangostana $(5 \mathrm{mg} / \mathrm{mL})$.

Group IV: Mice pretreated 1 week with green nanoparticles biosynthesized with G. mangostana ( $5 \mathrm{mg} / \mathrm{mL} /$ orally/day) and then infected with L. monocytogenes $10^{10} \mathrm{CFU}$ orally/day.

Two weeks postinfection, mice were sacrificed, and their intestinal tissues were excised promptly. Intestinal tissue samples for histopathological analysis were put in $10 \%$ formalin at $-80{ }^{\circ} \mathrm{C}$ until intestinal sections were processed, and for biochemical and molecular analyses, the samples were frozen at $-80^{\circ} \mathrm{C}$ without formalin until processed.

\subsection{Oxidative Stress}

Homogenates of the intestine were prepared in $50 \mathrm{mM}$ Tris- $\mathrm{HCl}$ and $300 \mathrm{mM}$ sucrose to measure lipid peroxidation (LPO) in terms of the amount of malondialdehyde (MDA) formed using the thiobarbituric acid (TBA) method by Ohkawa et al. (1979) [24].

\subsection{Enzymatic Antioxidant Status}

The prepared homogenates of the intestine were used in the determination of catalase (CAT) [25].

\subsection{Determination of Apoptotic Markers in Intestinal Tissue}

Intestinal homogenates were prepared in lysis buffer and analyzed using a colorimetric caspase-3 assay kit (Product number: CASP3C; Sigma-Aldrich Co. St. Louis, MO, USA) according to the manufacturer's instructions. The concentrations of caspase-3 in intestinal lysates were calculated with the help of the calibration curve generated using known amounts of standards. Bcl-2 (Cat. No. LS-F10920) levels were measured in the intestinal tissue lysates with ELISA kits (LifeSpan BioSciences, Inc., Seattle, WA, USA). The procedure was according to the instructions of the manufacturer. The levels are expressed as $\mathrm{ng} / \mathrm{mg}$ tissue protein. 


\subsection{Real-Time PCR}

Total RNA was extracted from the intestinal tissue samples using an RNeasy Plus Mini kit (Qiagen, Valencia, CA, USA). RNA was reverse transcribed using the RevertAid H Minus Reverse Transcriptase (Fermentas, Thermo Fisher Scientific Inc., Waltham, MA, USA). Real-time PCR reactions were performed using Applied Biosystems 7500 Instrument. The relative gene expression was determined with power SYBR Green (Life Technologies, Carlsbad, CA, USA) and by the comparative threshold cycle method of Pfaffl (2001) [26]. The PCR primers for TNF- $\alpha$ and $I L-1 \beta$ genes were synthesized by Jena Bioscience GmbH (Jena, Germany). Primers were designed using the Primer-Blast program from NCBI. mRNA levels for each sample were normalized to GAPDH. The following primer sets were used:

\begin{tabular}{ccc}
\hline Name & Sense $\mathbf{( \mathbf { 5 } ^ { \prime } - \mathbf { 3 } ^ { \prime } )}$ & Antisense $\mathbf{( 5}^{\prime} \mathbf{- \mathbf { 3 } ^ { \prime } )}$ \\
\hline$T N F-\alpha$ & AGAACTCAGCGAGGACACCAA & GCTTGGTGGTTTGCTACGAC \\
\hline$I L-1 \beta$ & GACTTCACCATGGAACCCGT & GGAGACTGCCCATTCTCGAC \\
\hline GAPDH & GCATCTTCTTGTGCAGTGCC & GATGGTGATGGGTTTCCCGT \\
\hline
\end{tabular}

\subsection{Histopathological Examination}

Tissue samples were fixed in $10 \%$ neutral formalin for $24 \mathrm{~h}$ and paraffin blocks were routinely processed for light microscopy. Slices of 4-5 $\mu \mathrm{m}$ were obtained from the prepared blocks and stained with hematoxylin and eosin (H\&E) as well as Masson's trichrome for fibrosis. The preparations obtained were visualized using a Nikon microscope at a magnification of 400×.

\subsection{Statistical Analysis}

Results represent means \pm standard errors of the means (SEM). Data were analyzed using the one-way analysis of variance (ANOVA). For comparison of significance between groups, Duncan's test was used as post hoc test according to the Statistical Package for the Social Sciences (SPSS version 20.0 IBM, Armonk, NY, USA).

\section{Results}

The total phenolic and flavonoids contents of the investigated extract were found to be 11.453 $\pm 0.934 \mathrm{mg}$ eq. gallic acid $/ \mathrm{g}$ and $0.725 \pm 0.034 \mathrm{mg}$ eq. rutin $/ \mathrm{g}$, respectively (Table 1 ). Furthermore, the results revealed that the extract has potent free radical scavenging power. For the DPPH, ABTS, and FRAB assays, the values obtained were $38.564 \pm 1.23,5.892 \pm 0.045$, and $0.245 \pm 0.0045 \mu \mathrm{mol}$ eq. Trolox/g, respectively.

Table 1. Experimental determinations of total phenolic and flavonoids contents and antioxidant capacity assays (ABTS, DPPH, and FRAB) for G. mangostana extract.

\begin{tabular}{cc}
\hline Parameters & Mean \pm SD \\
\hline Total phenols (mg eq. gallic acid/g sample) & $11.453 \pm 0.934$ \\
\hline Total flavonoids (mg eq. rutin/g sample) DPPH (\%) & $0.725 \pm 0.034$ \\
\hline DPPH (\%) & $38.564 \pm 1.23$ \\
\hline ABTS (_mol eq. Trolox/g sample) & $5.892 \pm 0.045$ \\
\hline FRAB (_mol eq. Trolox/g sample) & $0.245 \pm 0.0045$ \\
\hline
\end{tabular}

The UV-visible spectrophotometer was used in order to confirm the presence of Ag-NPs (Figure 1). As shown in Figure 1A, the graph shows the average particle size of Ag-NPs using the dynamic light scattering Zetasizer. This was the technique used to determine the size distribution profile of $G$. mangostana with Ag-NPs at $133.8 \mathrm{~nm}$ (Figure 1B). This result proved the homogenous distribution and size variation with no agglomeration of resulting nanoparticles, which was clearly indicated by the 
appearance of one peak. Furthermore, TEM image (Figure 2) demonstrated that most of the Ag-NPs were spherical or polygonal in morphology, with size up to $93.50 \mathrm{~nm}$. The color of the Ag-NPs in aqueous solution did not change, indicating the stability of the Ag-NPs.

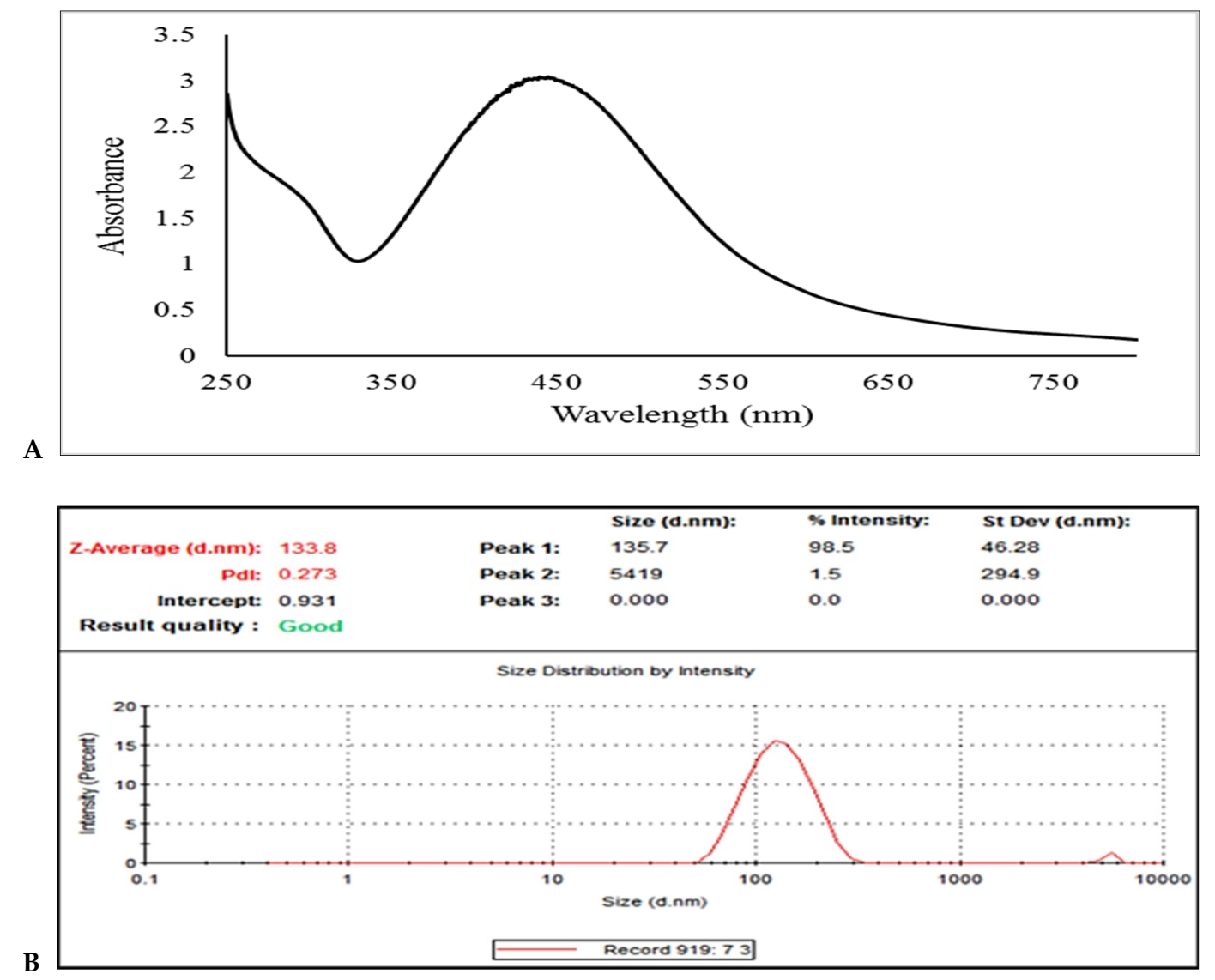

Figure 1. (A) The absorption spectrum of the green silver nanoparticles synthesized with G. mangostana and (B) a graph of a Zetasizer measurement of the average size of green Ag-NPs.
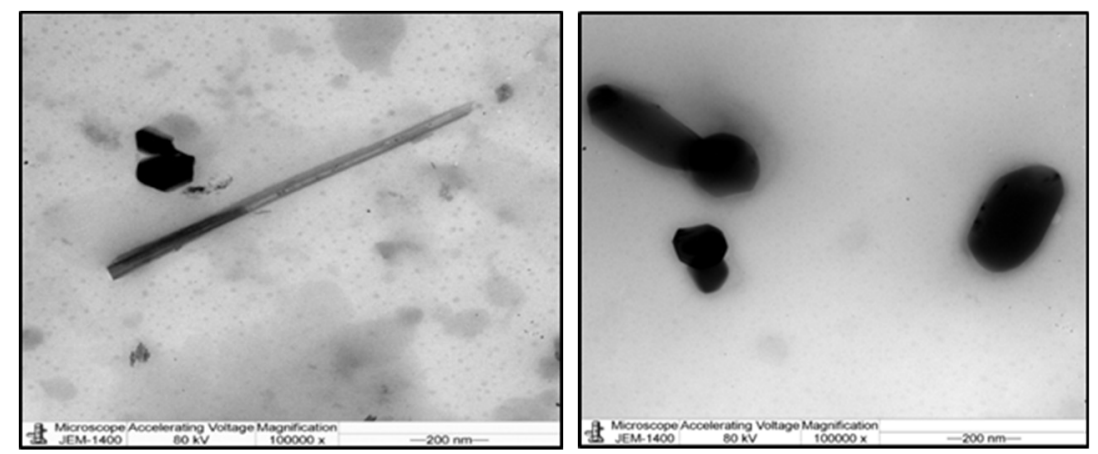

Figure 2. A graph of transition electron microscopy (TEM) image of green silver nanoparticles (Ag-NPs) synthesized (scale bar: $200 \mathrm{~nm}$ ).

L. monocytogenes infection significantly $(p<0.05)$ enhanced the formation of lipid peroxidation, which implicated in the pathogenesis of intestinal tissue injury by the free radical derivatives of $L$. monocytogenes and was responsible for cell membrane damage and consequent release of marker enzymes of intestinal toxicity. Malondialdehyde (MDA), a product of lipid peroxidation that is widely used as a marker of lipid peroxidation, was significantly increased in the small intestine homogenates 
(Figure 3), while increase in MDA was inhibited in the green NPs-treated groups compared to the control group.

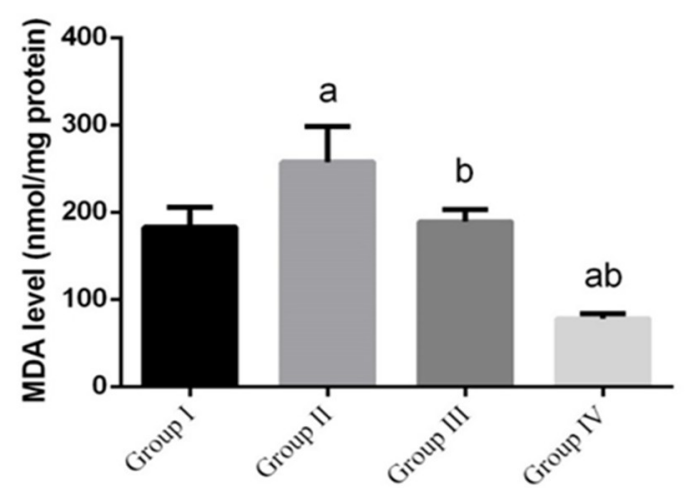

Figure 3. The effect of green Ag-NPs with G. mangostana on intestinal lipid peroxidation, (malondialdehyde, MDA) induced by L. monocytogenes $\left(10^{10} \mathrm{CFU} /\right.$ day). Values are means $\pm \mathrm{SEM}(\mathrm{n}=$ 7). ${ }^{\mathrm{a}} p<0.05$, significant change compared to control (noninfected negative control) group (G I) and ${ }^{\mathrm{b}} p$ $<0.05$, significant change compared to infected group (G II).

L. monocytogenes-infected mice (Figure 4) showed significant decrease in intestinal CAT, while it was significantly increased in green nanoparticles-treated groups, compared to the control group.

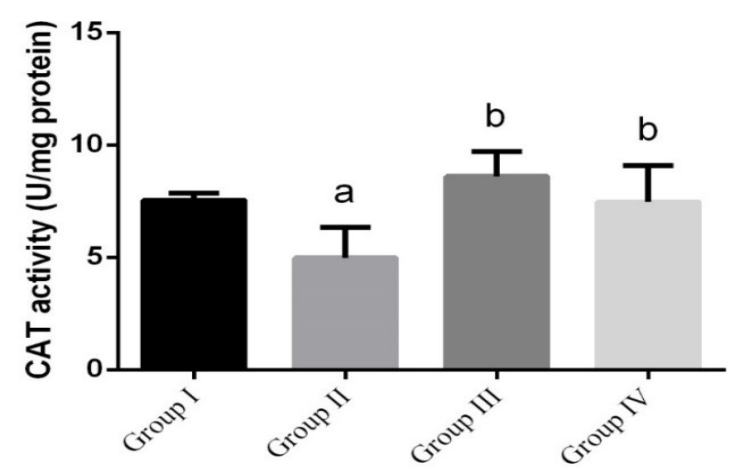

Figure 4. The effect of green Ag-NPs using G. mangostana on intestinal catalase (CAT) enzyme. Values are means \pm SEM $(n=7)$. ${ }^{a} p<0.05$, significant change compared to control (noninfected negative control) group (G I) and ${ }^{\mathrm{b}} p<0.05$, significant change compared to infected group (G II).

To investigate whether the observed antilisterial effects of green Ag-NPs were related to the antiapoptotic activity of green Ag-NPs, the protein levels of Bcl-2 in intestinal tissue were measured. The findings revealed that the antiapoptotic protein Bcl-2 was significantly reduced $(p<0.05)$. However, mice treated with green Ag-NPs, concurrently or prior to L. monocytogenes infection, showed significant increase in Bcl-2 (Figure 5).

During inflammation, the nucleus has a seminal role in immunity due to its active pro-inflammatory genes that encodes TNF- $\alpha$ and $I L-1 \beta$. The results showed a significant upregulation in the expression of TNF- $\alpha$ mRNA and IL-1 $\beta$ mRNA in the L. monocytogenes-infected groups (Figure 6) compared to the control group, while the green nanoparticles-treated groups showed a significant downregulation in gene expression level. 


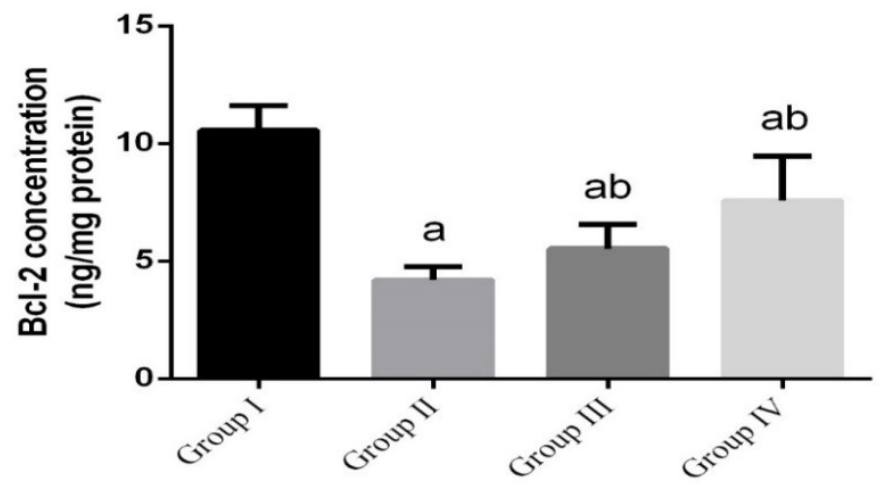

Figure 5. The effect of green Ag-NPs using G. mangostana on intestinal antiapoptotic protein (Bcl-2). Values are means \pm SEM $(n=7)$. ${ }^{a} p<0.05$, significant change compared to control (noninfected negative control) group (G I) and ${ }^{\mathrm{b}} p<0.05$, significant change compared to infected group (G II).

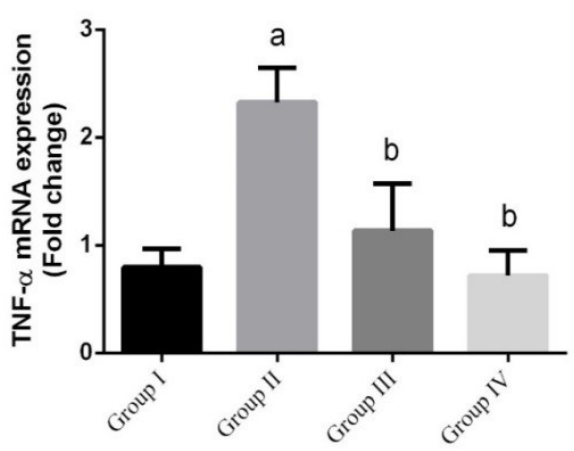

(A)

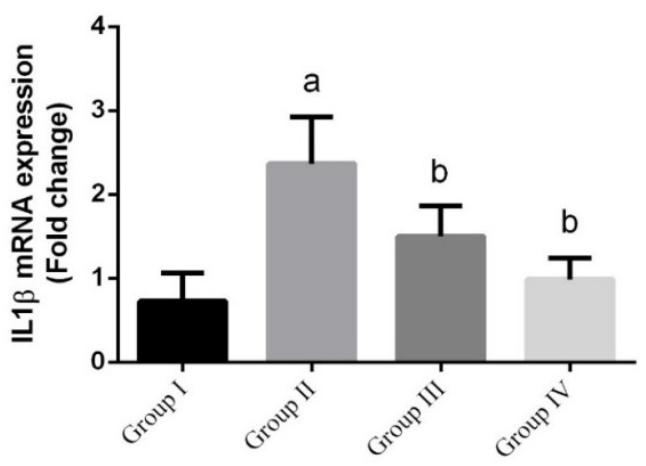

(B)

Figure 6. (A and B) The effect of green Ag-NPs with G. mangostana on intestinal gene expression of $I L-1 \beta$ mRNA and TNF- $\alpha$ mRNA induced by L. monocytogenes. Values are means \pm SEM $(n=7)$. a $p<0.05$, significant change compared to control (noninfected negative control) group (G I) and ${ }^{\mathrm{b}} p<0.05$, significant change compared to infected group (G II).

Histological patterns observed in the small intestine (Figure 7): normal structure was observed in the control noninfected group. The infected positive group showed destructed villi, degeneration of the lamina propria, and the nuclei of the columnar cells were lost and fused together to form membranous-like shape, while the infected group treated with green Ag-NPs using G. mangostana showed healthy intestinal sections with well-defined and enhanced villi. Moreover, the green Ag-NPs using G. mangostana protected group showed degeneration in the lamina propria. 

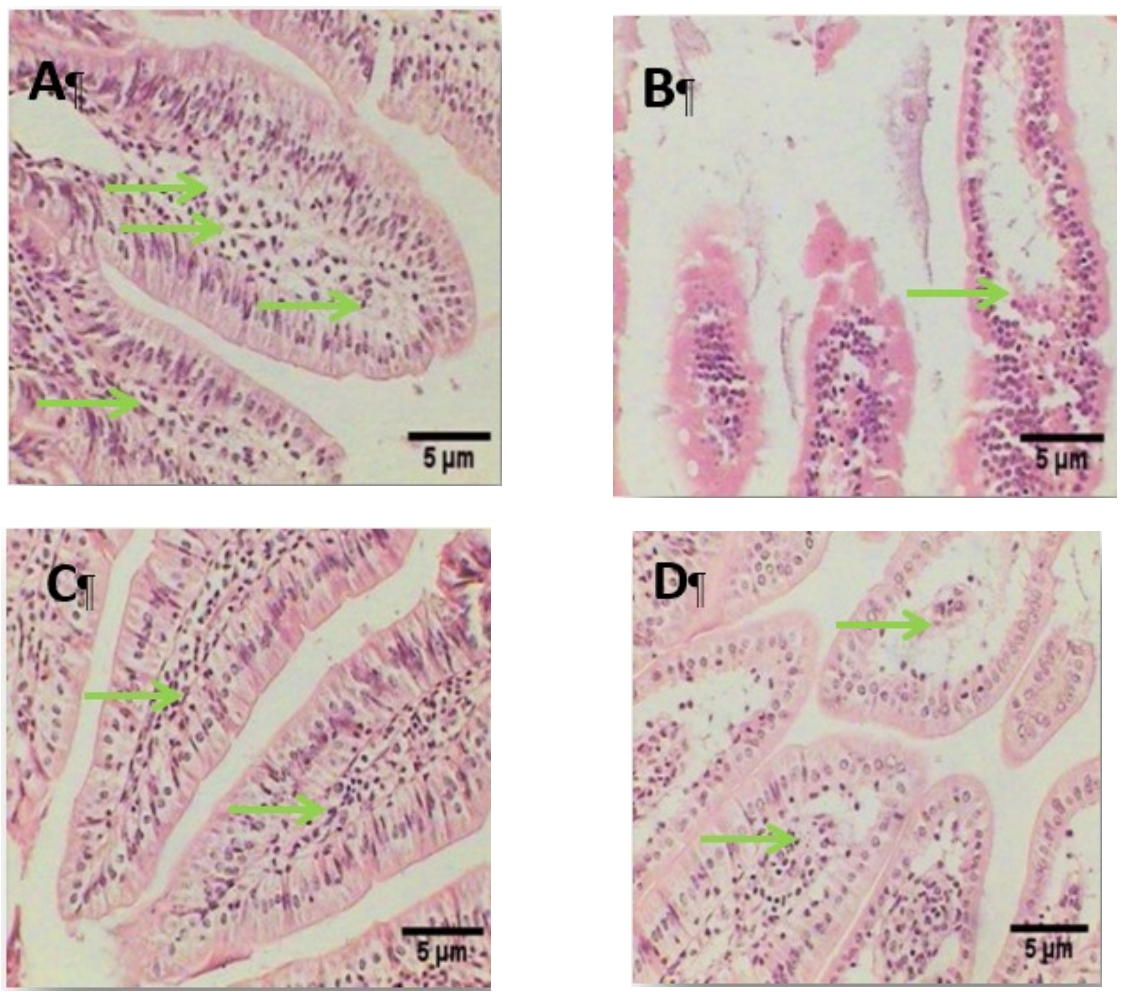

Figure 7. Photomicrograph of intestinal tissue stained with $H \& E$ stain $(100 \times)$ showing (A) control group (G I), healthy structure in the mucosa layer (M), submucosa (S), muscularis, (MS), and normal healthy structure in the lamina propria (Lp) (B) Infected group (G II), showing a destructed villi (V) and degeneration of the lamina propria. (C) Infected group and treated the same time with green Ag-NPs using G. mangostana (G III) showing an enhanced villus with very little degeneration of lamina propria. (D) The protected group, given green Ag-NPs using G. mangostana and after 1 week infected with L. monocytogenes (G IV) showing a destructed villus. Green arrows indicate lamina propria (Lp).

\section{Discussion}

The small intestine is an important site of infection for many enteric bacterial pathogens, and serves as the site of colonization and attachment and the seat of pathogenesis for a number of important enteric bacterial pathogens of humans and animals [27]. The use of plants as the production assembly of Ag-NPs has drawn considerable attention because of its rapid, eco-friendly, nonpathogenic, and economical protocol and they provide a single-step technique for the biosynthetic processes. The reduction and stabilization of silver ions by combining it with biomolecules, such as proteins, amino acids, enzymes, polysaccharides, alkaloids, tannins, phenolics, saponins, and vitamins, which already exist in the plant extracts, have medicinal value [28].

In this study, green nanoparticles were evaluated against inflammatory listeriosis. The results showed that green nanoparticles were able to enhance immunogenicity as demonstrated by increased survival time, reduced pathological changes in intestinal tissue, and enhanced immune response [12].

Mangosteen contains the secondary metabolites xanthones, which are polyphenols [11]. The results indicated intestinal damage, induced by L. monocytogenes, with the evaluation of lipid peroxidation, which showed significantly elevated levels of MDA, the end product of lipid peroxidation in the infected untreated group. Several studies have suggested that the levels of MDA increase during bacterial infections due to the membrane damage caused by cytosolic LLO [25-27]. In this study, the groups treated with green Ag-NPs using G. mangostana showed decreased MDA levels due to the action of $\alpha$-mangostin from G. mangostana rind, which had shown to protect the mitochondria from peroxidative damages; our findings were, thus, in accordance with the results of previous studies [29-31]. 
The activities of the antioxidant enzyme CAT in mice infected with L. monocytogenes also decreased, wherein CAT detoxifies hydrogen to water. Thus, treatment with green Ag-NPs synthesized with G. mangostana extract may protect cells from damage, demise, and dysfunction caused by $L$. monocytogenes-induced oxidative stress. Our results obtained for antioxidant enzyme activities are similar to the results of other authors [13,32].

Apoptosis is initiated by various types of stimuli, including infections. To investigate the degree of apoptosis, the Bcl-2 antiapoptotic protein was measured in intestinal tissue homogenates. LLO is a pore-forming molecule, and a major virulence factor of Listeria. L. monocytogenes which induces murine lymphocyte apoptosis. The insertion of LLO into the mitochondrial membrane causes the release of cytochrome c. The insertion of LLO into the mitochondrial and/or endoplasmic reticulum membrane stimulates calcium efflux, thereby activating the calpain and/or caspases. LLO is responsible for mitochondrial network disruption along with a decrease in mitochondrial membrane potential and intracellular ATP levels. Once released, cytochrome c can bind to apoptotic protease-activating factor-1(Apaf-1) in the cytoplasm, forming a complex that can activate caspase- 9 with subsequent death induction [33]. Our results showed that the levels of Bcl-2 significantly decreased in the infected untreated group, while the groups treated with green Ag-NPs synthesized with rind of G. mangostana showed increased Bcl-2 levels. $\alpha$-mangostin contains the $\mathrm{C} 10$ hydrophobic tail extension, which confers potency to the compound, and is also implicated in the antiapoptotic action. Other studies have reported similar results [34-36].

The results of histopathological investigation showed that morphological changes in the infected group with L. monocytogenes at the dose of $10^{10} \mathrm{CFU} /$ day for 1 week induced apoptosis and severe damage and degeneration in intestinal cells, which were in agreement with several authors (Longhi et al., 2005 [37]; Hausmann, 2010 [38]). After exposure to L. monocytogenes, the apoptosis can be induced by mucosal factors secreted by epithelial cells. The pro-inflammatory cytokine (TNF- $\alpha$ ) is central to epithelial injury [38]. L. monocytogenes specifically targets its receptor on intestinal villi and crosses the intestinal barrier, and leads to the onset of a systemic infection [39]. This breakdown of the epithelial barrier plays a part in the disruption of epithelial defenses and further accelerates mucosal inflammation [38]). The study showed that the infected group and the group treated at the same time with green Ag-NPs using G. mangostana (G III) showed the best results compared with the protected group (G IV); this is due to the antioxidant and phenolic contents, particularly, $\alpha$-mangostin, found in the rind of G. mangostana fruit that stabilize and maintain the integrity of the intestinal tissue, i.e., protect against the apoptosis damage. Our findings were similar with Chen et al., 2018 [40] and Jindarat, 2014 [41]; they found that mangosteen inhibited the pro-inflammatory cytokines and decreased TNF- $\alpha$ production.

The histopathological investigation revealed that L. monocytogenes caused progressive alterations in the small intestine; this result was in agreement with several studies (Becattini et al., 2017 [7]; Markus \& Martin, 2010 [42]; Sukhadeo \& Trinad, 2009 [43].

There are many cytokines participated in inflammatory response such as tumor necrosis factor alpha (TNF- $\alpha$ ) and interleukin-1 beta (IL-1 $\beta$ ) which both play central roles in inflammation. TNF-alpha signals through two distinct membrane-bound receptors (TNFR1 and TNFR2); the two receptors share many intracellular signaling intermediates, including nuclear factor kappa-light-chain-enhancer of activated B cells (NF- $\mathrm{kB}$ ), and thus, together may enhance inflammatory mediator production. Furthermore, IL-1 $\beta$ activates similar signaling pathways as TNF- $\alpha$ to induce primarily pro-inflammatory gene expression (PMC2718541) [44,45]. Inflammation plays an important role in host defense, which encompasses multiple processes against external stimuli such as infection by pathogen, exposure to bacterial endotoxin, or chemical exposure.

In this study, we evaluated the effect of green Ag-NPs using G. mangostana, as anti-inflammatory response inhibited by signaling cascade of pro-inflammatory gene expression, which in contrast showed a significant upregulated response in the TNF- $\alpha$ and $I L-1 \beta$ gene expression levels caused by L. monocytogenes infection compared to the control group; this result was similar with $[5,45]$. Several 
studies have suggested that the phytochemical in green nanoparticles caused a significant decrease in the gene expression levels due to the $\alpha$-mangostin found in the G. mangostana fruit, which is able to lower the levels of inflammatory proteins [46-49].

\section{Conclusions}

In conclusion, treatment with green Ag-NPs was more effective in inhibiting the development of intestinal toxicity by decreasing oxidative stress, downregulating pro-inflammatory cytokines genes, as well as improving the histological features of the small intestine.

Supplementary Materials: The following are available online at http://www.mdpi.com/2076-2615/10/4/573/s1, Table S1: content of total phenols, flavonoids, and antioxidant activity of flavonoids free-radical scavenging (DPPH and ABTS) and ferric reducing antioxidant power (FRAP) in methanol-extracted air- and freeze-dried mangosteen peel nanoparticles, Figure S1: total viable count of Listeria monocytogenes ATCC 19114 against optical density at 620 nm, Figure S2: optical density of Listeria monocytogenes ATCC 19114 at $620 \mathrm{~nm}$ at different time per hours.

Author Contributions: M.F.E.-K. and H.M.Y. conceived and designed the experiments; N.A.M. performed the experiments; A.F.A. and S.A. analyzed the data; N.A.M., M.A.A., and A.R.K. contributed reagents/materials/analysis tools; M.F.E.-K. and N.A.M. wrote the paper. All authors have read and agreed to the published version of the manuscript.

Funding: This research was funded by Deanship of Scientific Research at King Saud University, Grant number RG-1435-016.

Acknowledgments: The authors would like to extend their sincere appreciation to the Deanship of Scientific Research at King Saud University for funding this research through the Research Group project no. RG-1435-016.

Conflicts of Interest: The authors declare no conflicts of interest.

\section{References}

1. Denbow, M. Gastrointestinal anatomy and physiology. In Sturkie's Avian Physiology, 6th ed.; Academic Press: San Diego, CA, USA, 2015; pp. 337-366.

2. $\quad$ Eckburg, P.B.; Bik, E.M.; Bernstein, C.N.; Purdom, E.; Dethlefsen, L.; Sargent, M.; Gill, S.R.; Nelson, K.E.; Relman, D.A. Diversity of the human intestinal microbial flora. Science 2005, 308, 1635-1638. [CrossRef] [PubMed]

3. Khumsupan, P.; Gritsanapan, W. Anti-acne activity of Garcinia mangostana L.: A review. Plant Sci. Today 2014, 1, 147-150. [CrossRef]

4. Hitchins, A.D. Listeria monocytogenes-Detection by chemiluminescent DNA hybridization. In Encyclopedia of Food Microbiology, 2nd ed.; Batt, C.A., Tortorello, M.L., Eds.; Elsevier: Amsterdam, The Netherlands, 2014; pp. 494-500.

5. Lin, H.; Gao, D.; Hu, M.M.; Zhang, M.; Wu, X.-X.; Feng, L.; Xu, W.-H.; Yang, Q.; Zhong, X.; Wei, J.; et al. MARCH3 attenuates IL-1 $\beta$-triggered inflammation by mediating K48-linked polyubiquitination and degradation of IL-1RI. Proc. Natl. Acad. Sci. USA 2018, 115, 12483-12488. [CrossRef] [PubMed]

6. Wehkamp, J.; Götz, M.; Herrlinger, K.; Steurer, W.; Stange, E.F. Inflammatory bowel disease: Crohn's disease and ulcerative colitis. Dtsch. Arztebl. Int. 2016, 113, 72-82. [CrossRef] [PubMed]

7. Becattini, S.; Littmann, E.R.; Carter, R.A.; Kim, S.G.; Morjaria, S.M.; Ling, L.; Gyaltshen, Y.; Fontana, E.; Taur, Y.; Leiner, I.M.; et al. Commensal microbes provide first line defense against Listeria monocytogenes infection. J. Exp. Med. 2017, 214, 1973-1989. [CrossRef] [PubMed]

8. Dkhil, M.A.; Moneim, A.E.; Al-Quraishy, S. Indigofera oblongifolia ameliorates lead acetate-induced testicular oxidative damage and apoptosis in a rat model. Biol. Trace Elem. Res. 2016, 173, 354-361. [CrossRef]

9. Nazre, M. New evidence on the origin of mangosteen (Garcinia mangostana L.) based on morphology and ITS sequence. Genet. Resour. Crop Evol. 2014, 61, 1147-1158. [CrossRef]

10. Gutierrez-Orozco, F.; Failla, M.L. Biological activities and bioavailability of mangosteen xanthones: A critical review of the current evidence. Nutrients 2013, 5, 3163-3183. [CrossRef]

11. Ayman, E.L.; Hassan, S.M.; Osman, H.E.H. Mangosteen (Garcinia mangostana L.). In Nonvitamin and Nonmineral Nutritional Supplements, 1st ed.; Nabavi, S., Silva, A.S., Eds.; Academic Press: London, UK; San Diego, CA, USA, 2019; pp. 313-319. 
12. Rajakannu, S.; Shankar, S.; Perumal, S.; Subramanian, S.; Dhakshinamoorthy, G.P. Biosynthesis of silver nanoparticles using Garcinia mangostana fruit extract and their antibacterial, antioxidant activity. Int. J. Curr. Microbiol. Appl. Sci. 2015, 4, 944-952.

13. Tsai, S.Y.; Chung, P.C.; Owaga, E.E.; Tsai, I.J.; Wang, P.Y.; Tsai, J.I.; Yeh, T.S.; Hsieh, R.H.; Hsieh, R.H. Alpha-mangostin from mangosteen (Garcinia mangostana Linn.) pericarp extract reduces high fat-diet induced hepatic steatosis in rats by regulating mitochondria function and apoptosis. Nutr. Metab. 2016, 13, 88. [CrossRef]

14. El-Khadragy, M.; Alolayan, E.M.; Metwally, D.M.; El-Din, M.F.S.; Alobud, S.S.; Alsultan, N.I.; Alsaif, S.S.; Awad, M.A.; Abdel Moneim, A.E. Clinical efficacy associated with enhanced antioxidant enzyme activities of silver nanoparticles biosynthesized using moringa oleifera leaf extract, against cutaneous leishmaniasis in a murine model of leishmania major. Int. J. Environ. Res. Public Health 2018, 15, 1037. [CrossRef] [PubMed]

15. Allahverdiyev, A.M.; Abamor, E.S.; Bagirova, M.; Ustundag, C.B.; Kaya, C.; Kaya, F.; Rafailovich, M. Antileishmanial effect of silver nanoparticles and their enhanced antiparasitic activity under ultraviolet light. Int. J. Nanomed. 2011, 6, 2705-2714. [CrossRef] [PubMed]

16. Ch, W.; Hn, M.; Ej, H.; Ky, P. Improved production of caffeic acid derivatives in suspension cultures of Echinacea purpurea by medium replenishment strategy. Arch. Pharm. Res. 2007, 30, 945-949.

17. Baba, S.A.; Malik, S.A. Determination of total phenolic and flavonoid content, antimicrobial and antioxidant activity of a root extract of Arisaema jacquemontii Blume. J. Taibah Univ. Sci. 2015, 9, 449-454. [CrossRef]

18. Akillioglu, H.G.; Karakaya, S. Changes in total phenols, total flavonoids, and antioxidant activities of common beans and pinto beans after soaking, cooking, and in vitro digestion process. Food Sci. Biotechnol. 2010, 19, 633-639. [CrossRef]

19. Gouveia, S.; Castilho, P.C. Antioxidant potential of artemisia argentea l'hér alcoholic extract and its relation with the phenolic composition. Food Res. Int. 2011, 44, 1620-1631. [CrossRef]

20. Benzie, I.F.F.; Strain, J.J. The ferric reducing ability of plasma (FRAP) as a measure of "antioxidant power": The FRAP assay. Anal. Biochem. 1996, 239, 70-76. [CrossRef]

21. Angelakopoulos, H.; Loock, K.; Sisul, D.M.; Jensen, E.R.; Miller, J.F.; Hohmann, E.L. Safety and shedding of an attenuated strain of Listeria monocytogenes with a deletion of actA/plcB in adult volunteers: A dose escalation study of oral inoculation. Infect. Immun. 2002, 70, 3592-3601. [CrossRef]

22. Lecuit, M.; Dramsi, S.; Gottardi, C.; Fedor-Chaiken, M.; Gumbiner, B.; Cossart, P. A single amino acid in E-cadherin responsible for host specificity towards the human pathogen Listeria monocytogenes. EMBO J. 1999, 18, 3956-3963. [CrossRef]

23. Golnazarian, C.A.; Donnelly, C.W.; Pintauro, S.J.; Howard, D.B. Comparison of Infectious Dose of Listeria monocytogenes F5817 as Determined for Normal Versus Compromised C57B1/6J Mice. J. Food Prot. 1989, 52, 696-701. [CrossRef]

24. Ohkawa, H.; Ohishi, N.; Yagi, K. Assay for lipid peroxides in animal tissues by thiobarbituric acid reaction. Anal. Biochem. 1979, 95, 351-358. [CrossRef]

25. Aebi, H. Catalase in vitro. Methods Enzymol. 1984, 105, 121-126. [CrossRef] [PubMed]

26. Pfaffl, M.W. A new mathematical model for relative quantification in real-time rt-pcr. Nucleic Acids Res. 2001, 29, e45. [CrossRef] [PubMed]

27. Garner, C.D.; Antonopoulos, D.A.; Wagner, B.; Duhamel, G.E.; Keresztes, I.; Ross, D.A.; Young, V.B.; Altier, C. Perturbation of the small intestine microbial ecology by streptomycin alters pathology in a Salmonella enterica serovar typhimurium murine model of infection. Infect. Immun. 2009, 77, 2691-2702. [CrossRef] [PubMed]

28. Narendra, K.; Uday, M. Biosynthesis of metal nanoparticles: A review. J. Nanotechnol. 2014, 2014. [CrossRef]

29. Dubovskiy, I.M.; Martemyanov, V.V.; Vorontsova, Y.L.; Rantala, M.J.; Gryzanova, E.V.; Glupov, V.V. Effect of bacterial infection on antioxidant activity and lipid peroxidation in the midgut of Galleria mellonella L. larvae (Lepidoptera, Pyralidae). Comp. Biochem. Physiol. Part C Toxicol. Pharmacol. 2008, 148, 1-5. [CrossRef]

30. Zhu, H.; Santo, A.; Jia, Z.; Li, Y.R. GPx4 in bacterial infection and polymicrobial sepsis: Involvement of ferroptosis and pyroptosis. React. Oxyg. Species 2019, 7, 154. [CrossRef]

31. Seveau, S. Multifaceted activity of listeriolysin O, the cholesterol-dependent cytolysin of Listeria monocytogenes. Subcell. Biochem. 2014, 80, 161-195.

32. Taher, M.; Susanti, D.; Rezali, M.F.; Zohri, F.S.A.; Ichwan, S.J.A.; Alkhamaiseh, S.I.; Ahmad, F. Apoptosis, antimicrobial and antioxidant activities of phytochemicals from Garcinia malaccensis Hk. f. Asian Pac. J. Trop. Med. 2012, 5, 136-141. [CrossRef] 
33. Chen, L.G.; Yang, L.L.; Wang, C.C. Anti-inflammatory activity of mangostins from Garcinia mangostana. Food Chem. Toxicol. 2008, 46, 688-693. [CrossRef]

34. Jaisupa, N.; Moongkarndi, P.; Lomarat, P.; Samer, J.; Tunrungtavee, V.; Muangpaisan, W.; Mangmool, S. Mangosteen peel extract exhibits cellular antioxidant activity by induction of catalase and heme oxygenase-1 mRNA expression. J. Food Biochem. 2018, 42, e12511. [CrossRef]

35. Al-Olayan, E.M.; El-Khadragy, M.F.; Metwally, D.M.; Moneim, A.E.A. Protective effects of pomegranate (Punica granatum) juice on testes against carbon tetrachloride intoxication in rats. BMC Complement Altern. Med. 2014, 14, 164. [CrossRef] [PubMed]

36. Carrero, J.A.; Calderon, B.; Unanue, E.R. Listeriolysin O from Listeria monocytogenes is a lymphocyte apoptogenic molecule. J. Immunol. 2004, 172, 4866-4874. [CrossRef] [PubMed]

37. Longhi, C.; Conte, M.P.; Ranaldi, S.; Penta, M.; Valenti, P.; Tinari, A.; Superti, F.; Seganti, L. Apoptotic death of Listeria monocytogenes-infected human macrophages induced by lactoferricin $\mathrm{B}$, a bovine lactoferrin-derived peptide. Int. J. Immunopathol. Pharmacol. 2005, 18, 317-325. [CrossRef] [PubMed]

38. Hausmann, M. How bacteria-induced apoptosis of intestinal epithelial cells contributes to mucosal inflammation. J. Inflamm. Res. 2010, 1-9. [CrossRef] [PubMed]

39. Nikitas, G.; Deschamps, C.; Disson, O.; Niault, T.; Cossart, P.; Lecuit, M. Transcytosis of Listeria monocytogenes across the intestinal barrier upon specific targeting of goblet cell accessible E-cadherin. J. Exp. Med. 2011, 208, 2263-2277. [CrossRef] [PubMed]

40. Chen, G.; Li, Y.; Wang, W.; Deng, L. Bioactivity and pharmacological properties of $\alpha$-mangostin from the mangosteen fruit: A review. Expert Opin. Ther. Pat. 2018, 28, 415-427. [CrossRef]

41. Jindarat, S. Xanthones from mangosteen (Garcinia mangostana): Multi-targeting pharmacological properties. J. Med. Assoc. Thai. 2014, 97, S196-S201.

42. Markus, S.; Martin, J.L. The Opportunistic Pathogen Listeria monocytogenes: Pathogenicity and Interaction with the Mucosal Immune System. Int. J. Inflamm. 2010, 2010, 704321.

43. Sukhadeo, B.B.; Trinad, C. Molecular mechanisms of bacterial infection via the gut. Curr. Top. Microbiol. Immunol. 2009, 337, 173-195.

44. Hatice, Y. Apoptosis and Infections. In Cell Death-Autophagy, Apoptosis and Necrosis. Intech. Open. 2015. [CrossRef]

45. Wajant, H.; Siegmund, D. TNFR1 and TNFR2 in the Control of the Life and Death Balance of Macrophages, Front. Cell Dev. Biol. 2019, 7, 29.

46. Aizat, W.M.; Jamil, I.N.; Ahmad-Hashim, F.H.; Noor, N.M. Recent updates on metabolite composition and medicinal benefits of mangosteen plant. PeerJ 2019, 7, e6324. [CrossRef] [PubMed]

47. Lopez-Castejon, G.; Brough, D. Understanding the mechanism of IL-1 $\beta$ secretion. Cytokine Growth Factor Rev. 2011, 22, 189-195. [CrossRef] [PubMed]

48. Uchiyama, R.; Yonehara, S.; Tsutsui, H. Fas-mediated inflammatory response in Listeria monocytogenes infection. J. Immunol. 2013, 190, 4245-4254. [CrossRef] [PubMed]

49. Bumrungpert, A.; Kalpravidh, R.W.; Chitchumroonchokchai, C.; Chuang, C.C.; West, T.; Kennedy, A.; McIntosh, M. Xanthones from mangosteen prevent lipopolysaccharide-mediated inflammation and insulin resistance in primary cultures of human adipocytes. J. Nutr. 2009, 139, 1185-1191. [CrossRef]

(C) 2020 by the authors. Licensee MDPI, Basel, Switzerland. This article is an open access article distributed under the terms and conditions of the Creative Commons Attribution (CC BY) license (http://creativecommons.org/licenses/by/4.0/). 